\title{
Time-Course of Diuresis During Sodium-Aided Hyperhydration Protocols With and Without Caffeine
}

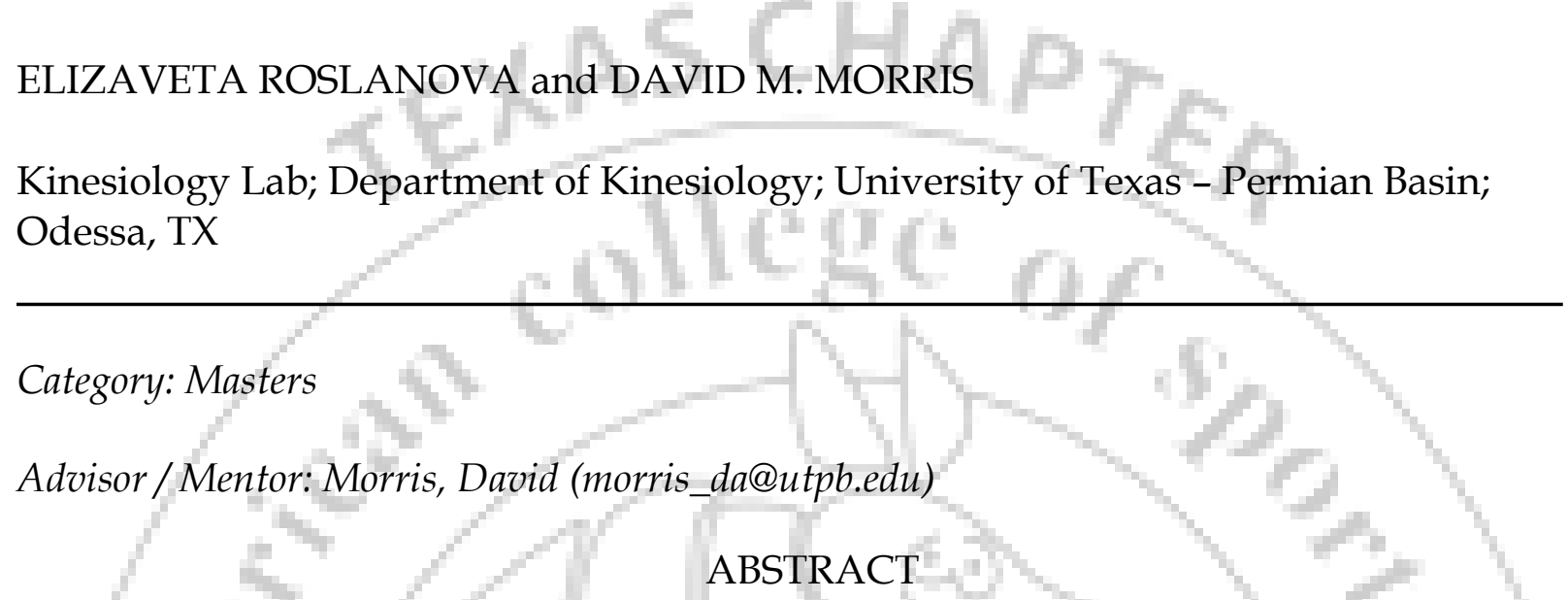

When used alone, both caffeine and sodium-aided hyperhydration (SAH) are ergogenic. When caffeine is used in conjunction with SAH, diuresis occurs, but hyperhydration is still achieved albeit at lower levels when compared to SAH alone. Caffeine has been shown to be ergogenic when taken as little as $5 \mathrm{~min}$, or as much as $6 \mathrm{hr}$ prior to the start of exercise. Thus, determining the temporal aspects of caffeine induced diuresis when used in conjunction with SAH may lead to superior pre-exercise nutritional strategies. PURPOSE: To investigate the time-course of caffeine-induced diuresis during a $90 \mathrm{~min}$ SAH protocol. METHODS Subjects were 15 males $(21 \pm 2 \mathrm{yr}, 176 \pm 6 \mathrm{~cm}, 80.2 \pm 10.1 \mathrm{~kg})$ free from known renal, digestive, and cardiovascular disease. Each underwent 2 hyperhydration strategies in a randomized, double-blind fashion. Both protocols began with a complete bladder void and measurement of urine specific gravity (USG) followed immediately by ingestion of a bolus of $20 \mathrm{~mL} \mathrm{H}_{2} \mathrm{O} \cdot \mathrm{kg} \mathrm{bm}^{-1}$ combined with either $110 \mathrm{mg}$ $\mathrm{NaCl} \cdot \mathrm{kg} \mathrm{bm}^{-1}(\mathrm{Na})$, or $5 \mathrm{mg}$ caffeine $\cdot \mathrm{kg} \mathrm{bm}^{-1}+110 \mathrm{mg} \mathrm{NaCl} \cdot \mathrm{kg} \mathrm{bm}^{-1}(\mathrm{CafNa})$. Subjects then rested quietly for $90 \mathrm{~min}$, performing a measured bladder void every $15 \mathrm{~min}$. Urine excretions were expressed as a percentage of the total fluid consumed during each of the hyperhydration protocols. USG and total urine excreted (TUE) during the trials were compared using paired t-tests. Urine excretion (UE) for each of the 15 min collection periods for the two conditions were compared using a two-way repeated measures ANOVA with Sidak post hoc analyses. Levels of significance were set a priori at $\mathrm{P}<0.05$. RESULTS: USGs were $1.007 \pm 0.003(\mathrm{Na})$ and $1.005 \pm 0.004(\mathrm{CafNa})(\mathrm{P}=0.34)$. TUE were $62.7 \pm 13.2 \%(\mathrm{Na})$ and $78.7 \pm 12.5 \%$ (CafNa) $(\mathrm{P}=0.001)$. UE for the $\mathrm{Na}$ and CafNa for each collection period respectively were 13.1 $\pm 7.5 \%, 21.9 \pm 12.9 \%$ (15 min, $\mathrm{P}<0.01$ ), $11.7 \pm 3.3 \%, 13.8 \pm 3.8 \%$ (30 min, $\mathrm{P}=.30), 13.2 \pm 2.8 \%, 15.3 \pm 2.4 \%$ (45 min, $\mathrm{P}=0.32), 12.2 \pm 4.1 \%, 13.7 \pm 5.1 \%(60 \mathrm{~min}, \mathrm{P}=0.46), 8.4 \pm 6.3 \%, 8.9 \pm 4 \%(75 \mathrm{~min}, \mathrm{P}=0.80)$ and $4.7 \pm 3.6 \%$, $4.4 \pm 2.8 \%$ (90 min $\mathrm{P}=0.87$ ).CONCLUSION: TUE was significantly higher in CafNa compared to Na; however, caffeine induced diuresis occurred only during the initial $15 \mathrm{~min}$ following consumption of the treatments. 